\title{
Do discurso poético de Knopfli: uma leitura para além da base linguística
}

Paula Terra Nassr ${ }^{1}$

\begin{abstract}
Resumen: Este artículo trata de la obra poética del escritor mozambicano Rui Knopfli con base en la noción de Condiciones de Producción del discurso (CP) proveniente de los estudios del Análisis del Discurso Francés. El análisis de la poética del autor, bajo esa perspectiva, permite que tengamos una lectura del contexto histórico-social, posibilitando la emergencia de sentidos otros que no serían observados si nos guiásemos sólo por la base lingüística.
\end{abstract}

Palabras clave: Rui Knopfli; discurso poético; Condiciones de Producción.

Resumo: Este estudo trata da obra poética do escritor moçambicano Rui Knopfli com base na noção de Condições de Produção do discurso (CP) advinda dos estudos da Análise do Discurso Francesa. A análise da poética do autor, sob essa perspectiva, permite que tenhamos uma leitura do contexto histórico-social, possibilitando a emergência de sentidos outros que não seriam observados se nos guiássemos apenas pela base linguística. Palavras-chave: Rui Knopfli; discurso poético; Condições de Produção.

\section{Introdução}

As Condições de Produção do discurso representam, consoante Courtine, "a articulação teórica entre a Linguística e a História: é o espaço na cena do teatro ou entre as cordas do ringue por onde passam as peripécias discursivas abrigadas pelas determinações da história" (2009, p. 53). Sendo assim, ao lermos os poemas de Rui Knopfli não podemos deixar de adentrar nos fatos históricos que eclodiam no período em que produzia sua obra. Cada verso, cada recorte discursivo, diz muito do poeta, diz muito sobre ser moçambicano, bem como nos apresenta um sujeito que não se enquadrava somente de um lado ou de outro: "Europeu, me dizem [...] mas africano sou."

O discurso poético de Knopfli tem como pano de fundo a transformação histórica de seu país - Moçambique, vivia-se num clima tenso devido às lutas de libertação do colonialismo português. $\mathrm{O}$ discurso em voga era o revolucionário e quem não estivesse fortemente ligado a ele, acabava escapando pelas malhas da diáspora. Mesmo poetizando em forma de denúncia sobre os desmandos do período colonial em um contexto de "céu de chumbos e baionetas/gentes altivas sofrendo/nas margens do pão e da fome" (KNOPFLI, 2003, p. 37), o poeta nega-se a erguer seu discurso voltado puramente ao engajamento político. Desse modo, ele é acusado de desenraizado e de apátrida, sentindo-se um estranho na própria terra. Observamos, na escritura knopfliana, que há dissonâncias com o tom panfletário que estava presente na produção da maioria de seus contemporâneos, contudo ele nos apresenta imagens que fortalecem a denúncia e mostram um desejo de pertencimento. Sua escritura traz a consciência da cisão de seu lugar que, junto com o desencanto em relação à nação que o expulsou, leva-o a definir que "pátria é só a língua em que me digo.".

1 Doutora em Literatura Luso-africana pela UFRGS. Bolsista de Aperfeiçoamento Científico na Universidade Feevale. 
Desse modo, salientamos que, para se apresentar a obra poética de Knopfli em uma proposta pedagógica, é imprescindível que não o delimitemos a tipologias dos períodos literários dos círculos vigentes à sua época, mas que procuremos nos deter no discurso que está nas entrelinhas e nos ater à ordem da história, de modo a pensarmos que o estudo da poética knopfliana não pode estar separado das condições de produção desse discurso.

Neste trabalho, a partir de estudos bibliográficos teórico-críticos, abordaremos as condições de produção do discurso knopliano, observando que a leitura e o ensino de literatura através dos poemas se tornará ainda mais interessante quando tomamos conhecimento da história que transparece em cada verso.

Condições de Produção da obra de Rui Knopfli: contexto pré e pós-independência de Moçambique (1950-1975)

Quando fala em Condições de Produção (CP), Orlandi (1999) diz que essa noção compreende, fundamentalmente, os sujeitos e a situação, e que também a memória faz parte da produção do discurso. Ao considerarmos as CP em sentido estrito (circunstâncias da enunciação) temos o contexto imediato. E, ao considerá-las, em sentido amplo, incluímos o contexto sócio-histórico e ideológico. Logo, é muito importante saber em que condições um discurso foi proferido, em que momento histórico, em que circunstâncias, principalmente quando o discurso estiver embrenhado em um momento histórico como o de Moçambique no prenúncio da libertação do jugo colonial e nos primeiros momentos que o sucederam.

Em outro fragmento de discurso, Orlandi (1999, p. 40) especifica ainda mais a noção de condições de produção, diz ela que as

[...] condições de produção implicam o que é material (a língua sujeita a equívoco e a historicidade), o que é institucional (a formação social, em sua ordem) e o mecanismo imaginário. Esse mecanismo produz imagens dos sujeitos, assim como do objeto do discurso, dentro de uma conjuntura sócio-histórica.

A África ardia em chamas à época em que Rui Knopfli resenhava sua vida deslocada e fluida em versos visivelmente trazedores da influência dos cânones ocidentais; o que soava estranho se pensarmos na explícita orientação marxista constituinte da escritura dos intelectuais daquele momento da História. A literatura estava a serviço da guerra anticolonial e isto estava posto. Com o fim da Segunda Guerra Mundial, os movimentos de resistência à colonização tinham transformado as terras colonizadas em verdadeiros campos de batalha e de urgência de sentido. Os Estados de Direito interferiam com uma considerável importância na condição de "ser" e de "estar" dos sujeitos tanto da metrópole como das colônias. Ademais, acentuava-se, em um intento de solidificar espaços de nação, a proteção ao indivíduo, e uma espécie de arrependimento oficial regia o ordenamento compositor dos imaginários oficiais. Não é de se estranhar que no momento do desfazimento das estruturas coloniais, os poetas tendessem a estabelecer seu canto de modo a elevar a uma condição de audibilidade os conflitos que durante anos se arrastaram e devastaram seus países.

A urgência em [res]significar o avassalamento causado pela ação colonial conduzia a temática da literatura dos países de língua portuguesa em África. Ao colocar em debate a 
reconstrução da organização literária nos países colonizados por Portugal, Rita Chaves² afirma que desse

[...] debate não se excluem as remissões ao repertório literário e surgem, com alta frequência, os termos "angolanidade, caboverdianidade e moçambicanidade", revelando a preocupação quanto à ligação com o que seria considerado uma prática literária voltada para dentro dos países. A dialética entre o que é próprio e o que vem ou veio de fora ocupa ainda um importante terreno. Mesmo se, nos depoimentos dos escritores ou nos estudos críticos, esses conceitos vêm ganhando ou perdendo sentido em função da própria discussão sobre os processos históricos seguidos por essas sociedades com reflexos nas construções culturais que se vão formando, a discussão permanece acesa (CHAVES, 2005, p. 140).

Os modos de produção das literaturas africanas em língua portuguesa estão, nesse instante da história, vinculados a dois eixos fundamentais: o primeiro é que o espaço a ser habitado, e a partir do qual se efetuará uma efetiva produção de sentido artístico, é o espaço da guerra. Depois, os temas que recorrem nessas produções são, unissonamente, os de resistência e exaltação do espectro do nacionalismo dos países insurgentes, após o início da organização das Frentes de Libertação das nações africanas.

Esse período trará uma profícua produção em países como Angola, Cabo Verde e Moçambique, o que não significa que tal embate entre os sujeitos sociais e a história que lhes cabe, e ainda a exaltação de referentes nacionais, garantirá uma qualidade intrínseca às obras literárias. Muitos são os escritores nesse contexto; dentre eles, erguese, Rui Knopfli, que produziu a sua obra integrada em uma tradição de rigor comedido e desencantado e de sóbria discursividade em que convergem múltiplas raízes ocidentais antigas e modernas (LOPES; SARAIVA, 2012). A desfronteirização espacial e a habitação de lugares que propulsam uma memória mais contundente que alentadora, latentes em sua estética, fogem à materialização do senso comum. O poeta vai ocupar um espaço flutuante nas investigações sobre a literatura moçambicana, de um lado

[...] os que pretendem inscrevê-lo prioritariamente na tradição literária europeia, e do outro os que, sem lhe repudiarem inteiramente a condição de escritor ocidental, procuram no entanto lê-lo antes de mais como membro de uma geração fundadora dum discurso literário escrito moçambicano. Há também quem queira inseri-lo em um contexto de literatura colonial. A divergência de leituras não nasce com a independência de Moçambique e a tentativa dai decorrente de reconstituição e fixação dum corpus literário nacional, mas remonta ao periodo de pré-independência de Moçambique. Essa divergência vem-se mantendo até hoje, tendo Knopfli ganho o estatuto de "corpo de delito" em ambas as literaturas, moçambicana e portuguesa (MONTEIRO, 2003, p. 11).

Não são raras as vezes que os críticos não o fixam nos guetos conceituais. Na poética de Knopfli, há um prenúncio de uma diáspora íntima. Em sua obra Ensaios afro-literários (2001), o professor Pires Laranjeira divide as literaturas da África colonizada por Portugal em seis fases. Caracteriza-se a primeira fase pelo "baixo-romantismo", uma espécie de cópia da estética literária portuguesa. A segunda alcança os anos 80 e 90 do século

2 Professora Associada de Literaturas Africanas de Língua Portuguesa, da Faculdade de Filosofia, Letras e Ciências Humanas, da USP, é autora de obras fundamentais para os estudos literários das ex-colônias portuguesas na África, como Angola e Moçambique: o lugar das diferenças nas identidades em processo (2001), Angola e Moçambique - experiência colonial e territórios literários (2005), Marcas da diferença (2006) e A formação do romance angolano (1999). 
XIX, igualmente espelhada na metrópole, que será a realista em que o negro aparece em um patamar inferiorizado e com possibilidades de ascensão no trânsito social. No início do século XX, desde a primeira década, estendendo-se aos anos 40, Laranjeira a enquadra no que chama de Regionalismo africano, o que vai elevar o negro a um patamar de audibilidade dentro da representação artística pela influência - ainda que tênue - da africanidade negritudista.

O período que compreende a quarta fase das literaturas das ex-colônias portuguesas, vai dos anos 40 aos 60 do século passado, uma literatura de cunho marxista que o investigador chama de Casticismo, um sociorrealismo influenciado já pelo neorrealismo português e, também, pelo romance social do Brasil. A literatura de resistência vai aparecer na quinta fase. Os anos pós-independências, o autor denomina como a sexta fase, momento em que a literatura sofre violentas mudanças, como violentos são os movimentos da sociedade. Laranjeira ainda observa que

[...] o patriotismo inflama o estro literário e os ânimos cívicos por [...] vigorar certo estalinismo ideológico e estético [...] em que, por vezes, se combinam loas hagiográficas aos heróis da revolução e cânticos de exortação contra os agressores internos e externos, estes mediando guerras civis através daqueles (LARANJEIRA, 2001, p. 45).

Apesar de ter construído caracterizações que alcançam a quase-totalidade das manifestações literárias africanas, não consegue, o crítico, enquadrar Rui Knopfli em nenhuma destas caracterizações. Até mesmo a última que, genericamente, apela para as "significativas mudanças" sofridas pela arte literária, reflexo aderido às mudanças da ossatura antropológica, nem mesmo aí, nesta amplitude conceitual encontra-se o deslocado Knopfli. O poeta que esteve sempre na esquina do mundo, sempre nas fronteiras prestes a iniciar um canto outro de localização sazonal, não é enquadrado nas fissuras que as conceituações didáticas pretendem. Isso por ser demasiadamente humano, isso por escapar-se - orgânica e sistematicamente - do panfletarismo próidentitário da literatura da sua época.

Rui Knopfli vai partir de experiências muito diversas da maioria dos escritores e, com isso, fazer de sua ilha natal um mosaico de imagens, remexendo no baú das referências que carrega. Em sua poética vai aparecer a conturbação relacional com o país que se ergue, com a nação em montagem, consoante Rita Chaves (2005). É neste país que se amontoam anseios e tensões, caracterizadores de uma imagem maior de desalento. Um desalento político, espacial e referencial. O espaço de conforto sonhado, com a revolução em andamento, está em erosão com a vinda da organização da resistência e, mais tarde, com a independência. $\mathrm{O}$ que se pode afirmar desse sujeito-poético é que ele é parte de uma geração traída. Uma traição que vem dos desmandos da organização revolucionária, que vem da hostilidade que o espaço, agora impermeável, oferece. Em suas imagens poéticas serão articuladas marcas de angústia, de uma consciência atormentada e inserida em uma realidade histórica que requer certezas que ele não leva consigo, e exige precisões nas quais o poeta não se vê debruçado em seu fazer poético.

Para Rita Chaves, nos poemas de Rui,

[...] a ilha organiza-se como metáfora de uma ilha em desassossego, em um processo que mistura recusa e perseguição, muito distante de encontrar no terreno da subjetividade a serenidade que as monções ofereciam à difícil arte de navegar (2005, p. 215). 
A revolução silenciosa que Rui Knopfli estabelece permanentemente em seu fazer poético é a sublevação que foge às apologias nacionalistas, é a construção e a sedimentação de um espaço gestado pela palavra que o traz permeável e soberano, pronto a ser habitado por um sonhador. Em suas obras, as lembranças são engendradoras de imagens que flutuam entre o não engajamento com a verticalidade histórica e o conforto de possuir tais imagens como espaços de segurança. O aparente desvínculo da produção imediata de Knopfli com os processos históricos o descentra das conceituações periodísticas, é certo, mas o conduz à constituição de poeta que, ao tangenciar os movimentos imediatos da história, permanece nela de maneira plena e habitante, retendo um tempo que se comprime ao ser exposto à urgência de seu fazer poético. É Bachelard (1998, p. 28) que vai observar que, se quisermos ultrapassar

[...] a história, ou mesmo, permanecendo nela, destacar da nossa história a história sempre demasiado contingente dos seres que a sobrecarregam, perceberemos que o calendário de nossa vida só pode ser estabelecido em seu processo produtor de imagens.

Rui Knopfli busca nos espaços recriados por seus versos-memória a duração concreta da revolução, não a revolução que prostitui as palavras em palanques da subversão ideológica, mas uma sublevação de imagens que produzem um sentido de permanência, uma legítima representação íntima que descarta o supérfluo e organiza um espaço no qual se aninha a memória.

A produção literária africana contemporânea veio a emergir de uma situação de conflito e de busca de uma nova identidade nacional, que tinha de romper com padrões estéticos e temáticos estruturadores do discurso ocidental, do discurso dominante do colonizador. Além dos conflitos territoriais e políticos das guerras, havia o conflito de culturas, o poderoso lastro da herança europeia de um lado; e de outro, a realidade do negro com suas tradições, sua condição particular de um novo sujeito em um novo continente, buscando no meio da opressão reencontrar uma individualidade tão desfigurada ao longo de muitos anos de colonização.

É nesse entremeio que o poeta surge com seu discurso, que desqualifica a opressão colonizadora, mas que, ao mesmo tempo, não se enquadra no discurso meramente engajado. Esse distanciamento do discurso vigente fez com que o definissem como um sujeito desvinculado da sua pátria e lhe dessem o status de poeta sem lugar. Sob este conflito é que Knopfli produz sua obra poética que não deixa de ser crítica e que pretende ir além das fronteiras da marcha pela libertação, para além do discurso da descolonização e da obviedade pautada sobre dois polos opostos (dominados/dominantes). O fazer poético se torna o meio propício para esse sujeito conflitante ocupar um espaço que the foi negado. Octavio Paz (1993 p. 13) observa que o fazer poético é uma “operação capaz de mudar o mundo, a atividade poética é revolucionária por natureza; exercício espiritual é um método de liberação interior. A poesia revela este mundo; cria outro. [...] Convite à viagem; regresso à terra natal". O poeta se permite ir e vir sem restrições, de um modo atemporal, buscando manter um elo com sua pátria, sua terra, seu lar, a partir de um lugar imaginário que ele cria por conta de seus devaneios poéticos. Dessa forma, o sujeito não necessita estar presente para desfrutar das vivências em lugares por onde passou ou deseja passar, os seus desejos fluem e seus anseios são edificados pela palavra. No devaneio poético, de acordo com Bachelard (1998, p. 6), a alma está de vigília, sem tensão, repousada e ativa. De modo que para uma simples imagem poética não há projeto, 


\section{Conexão Letras}

"não lhe é necessário mais que um movimento da alma. Em uma imagem poética a alma afirma a sua presença". E ainda é a alma que vem habitar a forma, fazer com que deixe de ser qualquer coisa de um lugar-comum. A imaginação se torna mais importante que a própria vivência para o poeta.

O escritor Rui Knopfli produz a maior parte da sua obra poética em Moçambique, em um momento histórico de grande efervescência política. Ainda na elaboração do seu primeiro livro, o país vive sob domínio português, porém quando sai a publicação da sua primeira obra, O País dos outros, em 1959, uma crise já começa a ser instaurada e o Ministério do Exército português elabora uma política militar nacional de segurança e treinamento dos militares para uma provável guerra colonial, visto que já previa a possibilidade de situações mais difíceis com relação à segurança nos territórios ultramarinos.

A publicação do segundo livro de Knopfli, Reino Submarino, em 1962, vai coincidir com a fundação da FRELIMO - Frente de Libertação de Moçambique, por Eduardo Mondlane, que, nesse processo, se junta a intelectuais, estudantes e compatriotas vindos do exílio ou do interior do território.

Knopfli elabora seu discurso poético inserido em um imaginário político e social colonialista em que os sujeitos envolvidos pertenciam a, pelo menos, duas formações discursivas em confronto - a que seguia o ideal da colonização e a que a ele se opunha. Por isso, seria impossível viver nesse contexto sem apresentar um posicionamento. Entre o opressor e os oprimidos pelo sistema colonial, havia os sujeitos nascidos em terras ultramarinas e que tinham ascendência europeia, esta era a situação do poeta moçambicano, que como sujeito híbrido não poderia deixar de sofrer influência dos europeus e nem dos africanos.

Essa influência vinha por via intelectual, visto que era leitor fervoroso da literatura ocidental e, também, vinha do espaço cultural e social de onde nasceu e se criou. Participava de grupos de intelectuais moçambicanos que eram negros, mestiços e, extremamente reprimidos pelo sistema. $\mathrm{O}$ escritor era contra esse sistema repressor e sua obra vai apresentar esta característica, porém de forma bem menos panfletária do que o regime nacionalista exigia naquele momento histórico. Escreve uma poesia que revela, não a incapacidade de tomar partido, mas a capacidade de tomá-lo, seja cultural ou politicamente, contudo, valendo-se de um dizer metafórico.

A crítica que em um período de recrudescimento nacionalista de Moçambique dos anos 60 e 70, em que o que vigia era o debate aberto de questões sobre etnia e relações de poder, não admitia Knopfli como um legítimo escritor moçambicano, pois esses assuntos eram imprescindíveis para o reconhecimento da autenticidade literária africana. Contudo, o poeta recusava-se a aceitar a africanidade como essência, entendia-a como resultado de vivências, experiências e, por isso, rebatia as críticas, conforme observamos na entrevista concedida a Monteiro:

Eu não posso assumir as dores que não sinto. Eu posso reconhecer uma injustiça social larguíssima ou uma injustiça mais que social, que é a injustiça da situação colonial, [...] mas eu não posso vir falar do ponto de vista dos injustiçados. Só do meu ponto de vista. [...] O José Craveirinha tem uma importância na África de língua portuguesa a que eu não posso aspirar, nem deveria mencionar. Não sou mulato, não sofri na carne as humilhações, o preconceito, a discriminação... O que é que pretendiam, quando vinham lá com essas histórias das influências, a falar deste e daquele como fontes, geralmente moçambicanas, onde eu ia beber a inspiração? Que eu viesse fingir isso? Como posso fingir em verso o negro humilhado que não sou? [...] Para essa preocupação americana do politicamente correcto, estou-me as tintas. [...] 
O meu primeiro livro chamava-se O País dos Outros, já em 1959, por alguma razão. Aquilo não era para brancos. [...] Quando a FRELIMO tomou o poder, o inimigo era o português, estou convencido disso. Claro que havia um certo racismo, aliás compreensível, mas, mesmo aí, os brancos eram identificados com os portugueses (MONTEIRO 2003, p. 27).

Knopfli se sabia como uma voz discordante dos sistemas que vigiam à época de sua produção poética, não estava em consonância com o discurso colonialista, assim como não era aceito na sua condição de sujeito de ascendência lusitana por aqueles que entraram no poder após a independência em 1975, e isso tornava-o um exilado na sua pátria e, posteriormente, um sujeito diaspórico a vagar por terras estrangeiras.

Antes da sua saída ao exílio, o poeta publica em 1972 seu último livro, A Ilha de Próspero, ainda em terras africanas. Nesse mesmo ano, o clima de tensão entre civis e militares eclodiu em um incidente que foi importante para a decisão que conduziu ao 25 de abril, à Revolução dos Cravos em Portugal dois anos depois. Então, nesse ano de 1972, a ação militar da FRELIMO atingiu o centro do país onde havia forte presença de agricultores portugueses e algum desenvolvimento industrial.

No ano posterior, foi em direção ao distrito da Beira, e essa foi a primeira vez que o movimento atingia uma grande cidade do ponto de vista econômico e de concentração da população europeia. A população se encontrou ameaçada, e isso fez com que o clima de nervosismo se espalhasse.

Nas obras anteriores, Knopfli apresenta um discurso em que lamenta sua condição de fora do seu tempo, fora do espaço de aceitabilidade que tanto almejava para um cidadão africano de ascendência portuguesa, que não aceitava a condição colonial em que vivia seu país. Dizia em versos a situação de silenciamento em que era submetido: "Estrangulada nos fios a minha voz". (KNOPFLI, 2003, p. 55). "Simulo surdamente viver". (KNOPFLI, 2003, p. 61). O dizível, por vezes, não satisfazia, não produzia o efeito de sentido que cada silenciamento trazia junto com os modos do poeta sentir a sua história, o seu estágio de isolamento. O silêncio é um espaço de constituição do sujeito e dos sentidos.

Conforme Orlandi (1997), o silenciamento é parte da experiência da identidade, é parte do processo de identificação, é o que dá um espaço diferencial e condição de movimento, de reflexão. Mesmo antes de exilar-se de fato o escritor já sentia essa condição de afastamento da sua terra, e na sua obra A Ilha de Próspero, de 1972, anterior a sua saída de Moçambique, escreve um poema em que há um lamento, uma precoce recordação da sua ilha:

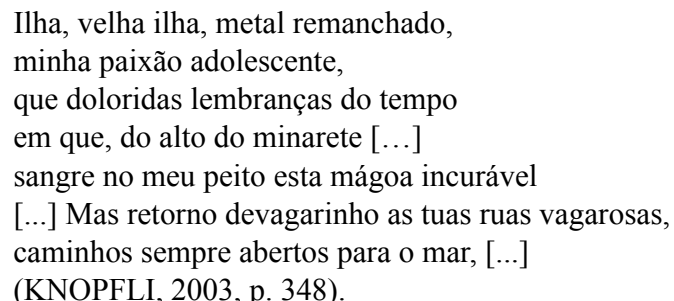

Que triste essa sensação de já quase partir, essa sensação de não mais pertencimento, esse modo de viver o presente como que povoado de sombras e fantasmas, que maculou cada verso, cada fragmento de discurso ao longo da sua obra, dando assim um tom melancólico e, em alguns momentos, nostálgico. 
Para fazermos uma leitura mais significativa dos poemas não deveremos nos deter nos aspectos linguísticos, exclusivamente, mas fazer um recorte discursivo onde possamos analisar o momento histórico referido nas entrelinhas, voltando-nos ao passado e aos fatos que são contados em cada verso. O sujeito falando da história do seu espaço, está nos mostrando como as condições de produção podem trazer à tona aspectos da vida social, do momento político, vindo a reboque sentidos que não poderíamos perceber se deixássemos a historicidade de lado. Dessa maneira, conhecendo o passado histórico, fazendo uma leitura da memória cultural e política, podemos entender os discursos do presente, bem como, os sentidos que advêm dos discursos produzidos a partir dessa relação passado-presente.

Nos fragmentos do poema a seguir, veremos como esses aspectos históricos aparecem e tornam os versos mais repletos de sentido.

As estações. A crueldade de Abril engendrando

flores, o ponteiro curando de impor ao quadrante

o rigor escamoteado pela fluidez da nebulosa,

o sangue ansioso entre a sístole e a diástole,

o sangue atónito entre o rumor e o silêncio

(KNOPFLI, 2003, p. 401).

Ao lermos o verso "A crueldade de Abril engendrando/flores", remetemo-nos à Revolução dos Cravos ocorrida em 25 de abril de 1974 em Portugal, um ano antes da independência de Moçambique do jugo colonial. Foi um movimento político e social que depôs o regime ditatorial do Estado Novo, vigente desde 1933, e que iniciou um processo que viria a terminar com a implementação de um regime democrático e com a entrada da nova constituição em 25 de abril de 1976. O período de crueldades passa a ser substituído por tempos mais democráticos e a simbologia dos cravos representa isso. No momento ápice da revolução uma senhora distribuía, junto com os demais populares, cravos vermelhos aos soldados e eles os colocaram nos canos das espingardas, daí o nome Revolução dos Cravos.

No discurso knopfliano, a palavra denunciante vem em forma de versos, primeiro vem o silêncio contemplador, depois vem a manifestação, que ao falar do silêncio, do medo, das sombras que foram impostos pelo processo histórico, mostra o quanto o sujeito poético quer romper com esse silenciamento, quer resistir e mostrar que as vozes ciciadas têm o direito de serem invocadas. Que tempos tristes foram retratados pelos versos de Knopfli, tempos em que os amanheceres banhados pela chuva, pelas sombras, pelos arrepios de medo, pela obscuridade, faziam dos sujeitos apenas coadjuvantes de um momento de dor, de não poderem ser de forma plena, de não poderem nem sequer elevarem as suas vozes.

Nos versos do poema "Dawn", a noite e o dia são uma imensa escuridão em meio ao silêncio:

\section{DAWN}

Agónica noite estremece

e despedaça-se

lá fora e chuva 
nas vidraças.

Das sombras, das solidões

dos recantos recônditos

da noite e da chuva

saem homens

Pela crosta da terra passa

um frémito de arrepio.

Chove.

Chove em África.

É noite.

É noite em África.

Mão desmedida ergue-se

no breu,

corpo da terra que as águas

fecundam, impregnam.

Silêncios, hesitações,

sono de séculos, jugos,

racham em surdina.

Jogamos bridge na tepidez

do living,

reclinamo-nos na morna

penumbra erótica

dos cinemas,

ou dormimos em calma

digestão.

Para lá

da noite angustiada

monótono acalanto ergue

a voz.

No inescrutável, nas sombras,

nos recantos recônditos de agónica noite

África desperta...

(KNOPFLI, 2003, p. 88-89).

A obra poética knopfliana vai refletir, por vezes, o propósito de redimir o espaço colonizado (Moçambique) de um estatuto de marginalidade e relocalizá-lo em relação ao mundo, geográfica e historicamente. Ao mesmo tempo, esse modo de exaltar a sua pátria de origem faz com que esse sujeito, de escrita historicamente relegada à marginalidade discursiva, recoloque-se, também, como sujeito poético dentro de seu espaço e de seu tempo de condição pós-colonial. Muitos de seus poemas vão ilustrar bem essa condição e essa relação com seu espaço, principalmente, representada pelo meio-ambiente e pela natureza de Moçambique (colonizado) comparado ao espaço europeu (do colonizador).

Os poemas abaixo evidenciam o que foi referido:

\section{HIDROGRAFIA}

São belos os nomes dos rios

na velha Europa.

Sena, Danúbio, Reno são

palavras cheias de suaves inflexões,

lembrando em tardes de oiro fino, 


\section{Conexão Letras}

frutos e folhas caindo, a tristeza outoniça dos chorões.

O Guadalquivir carrega em si espadas

de rendilhada prata, como o Genil ao sol-poente, o sangue de Federico.

E quantas histórias de terror contam as escuras águas do Reno?

Quantas sagas de epopeia não arrasta consigo a corrente do Dniepre.

Quantos sonhos destroçados navegam com detritos à superfície do Sena?

Belos como os rios são os nomes dos rios na velha Europa Desvendada, sua beleza flui sem mistérios.

Todo o mistério reside nos rios da minha terra.

Toda a beleza secreta e virgem que resta Está nos rios da minha terra.

[...]

Toda poesia oculta é a dos rios da minha terra.

[...]

Rios, seiva, ebuliente, veias, artérias, vivificadas dessa virgem morena e impaciente, minha terra, nossa Mãe!

(KNOPFLI, 2003, p. 121).

E segue:

\section{ILHA DOURADA}

A fortaleza mergulha no mar os cansados flancos e sonha com impossíveis naves moiras.

Tudo mais são ruas prisioneiras e casas velhas a mirar o tédio.

As gentes calam na voz uma vontade antiga de lágrimas e um riquexó de sono desce a Travessa da Amizade. Em pleno dia claro vejo-te adormecer na distância, Ilha de Moçambique, e faço-te esses versos de sal e de esquecimento (KNOPFLI, 2003, p.76). 
Knopfli, no poema "Hidrografia", apresenta um discurso que permite, na linguagem poética, a "reapropriação" do espaço colonial e sua restituição ao colonizado, ademais, aproxima-se do discurso da poesia brasileira, de Gonçalves Dias, ao exaltar a natureza de sua terra; e da poesia espanhola, de García Lorca, ao cantar os mistérios do "rio da minha terra" como faz o poeta espanhol com o Rio Guadalquivir. Tal direcionamento dialógico mostra a busca da consolidação de uma identidade nacional. Simultaneamente, vai desconstruir a imagem da glorificação épica como modo de questionar a autoridade moral da história do europeu e deslegitimizar o empreendimento colonial de devastação das colônias.

Ao contrastar dois mundos, o sujeito poético pretende construir uma relação de identificação com o espaço pós-colonial, como forma de afirmar sua africanidade, de transformar o ato poético em um ato discursivo de denúncia da história colonial e de mostrar-se sujeito ativo dentro dessa história.

Com um tom elegíaco, em "Ilha Dourada", o sujeito poético se confunde com o próprio espaço: "Tudo mais são ruas prisioneiras/e casas velhas a mirar o tédio". O sujeito poético é que se sente assim, prisioneiro, velho e devaneando sobre o sentimento de tédio e tristeza que o invade. Desse modo, como observa Bachelard (1998, p. 206), “dar seu espaço poético a um objeto é dar-lhe mais espaço do que ele tem objetivamente, ou melhor dizendo, é seguir a expansão de seu espaço íntimo”. O poema apresenta um discurso de lamento mútuo, compartilhado entre o sujeito poético: "faço-te estes versos/de sal e de esquecimento" e o sujeito colonizado nele representado por "as gentes calam na voz". Esse lamento expressa o sentimento de entendimento pelo sujeito da sua condição de exilado na sua pátria e que se vê invadido pelo colonizador, explicitado no poema pela fortaleza.

A palavra poética, nos versos dos poemas citados anteriormente, é reveladora da história, da agonia, da opressão simbólica, que nos desvela uma África e um sujeito abalados pelo sistema colonial, a poesia, segundo Octavio Paz, nasce no silêncio e no balbuciamento, no não poder dizer, mas aspira irresistivelmente à recuperação da linguagem como uma realidade total. "O poeta torna palavra tudo o que toca, sem excluir o silêncio [...] O poema acolhe o grito, os trapos vocabulares, a palavra gangrenada, o murmúrio, o ruído e o sem-sentido: não a in-significância” (PAZ, 2009, p. 120).

\section{Considerações finais}

Ao analisarmos a obra de Knopfli, observando as condições de produção, adentramos no momento histórico em que seu país vivia. Podemos comparar o período passado com o atual e fazer articulações culturais. Ao lermos os poemas baseando-nos na historicidade, retomamos fatos históricos e culturais do passado e recuperamos uma parte dessa memória via linguagem poética. Podemos ver emergir sentidos e junto com eles perceber como o sujeito poético se constitui. O sujeito fica, então, à deriva do seu tempo por não aceitar se engajar em uma funcionalidade estética, voltada a um panfletarismo, como faziam os demais poetas da sua época, fica à margem por inspirar-se nos cânones ocidentais em um tempo em que a ideia vigente se pautava em um sólido viés nacionalista e fugir, totalmente, das influências europeias.

O poeta segue o caminho diferente e isso custa-lhe a permanência em sua terra natal, obrigando-se a abandoná-la. Essa conjuntura histórica fez com que se tornasse um sujeito ocupante do entremeio das culturas euro-ocidental e africana. $\mathrm{O}$ conjunto de sua obra evidencia a tão conturbada relação que tinha com a situação histórica que movia a jovem nação, politicamente independente, no pós-1975; o que fazia emergir seus anseios de pertencimento e de territorialidade. 


\section{Conexão Letras}

Eis um fragmento que retrata o que foi referido: "Escrevo contra o silêncio. Eu/não tenho já nome aqui minha voz nasce/no deserto, vertical e desnuda, e rompe/lâmina cega, porém exacta; bate na pedra." (KONOPFLI, 2003, p. 406). Ao ensinarmos uma análise de texto poético apenas detendo-nos em métricas, períodos literários ou, ainda, fazendo unicamente uma análise comparativa com outras obras da mesma época, de modo a seguirmos uma leitura baseada na estrutura linguística, não chegaríamos no sentido que a palavra "abril", por exemplo, evoca no poema analisado anteriormente, o de que se referia à Revolução dos Cravos; bem como, não conseguiríamos perceber a melancolia dos versos, se não a relacionássemos às condições em que os sujeitos viviam no período da administração colonial portuguesa; não poderíamos interpretar o tom de denúncia se não soubéssemos que o sujeito que contrariasse o sistema colonialista ou que não se enquadrasse, totalmente, nas lutas de libertação, acabava por sentir-se deslocado.

Dessa forma, ao lançarmos um olhar à materialidade poética do autor, suportado pela noção de Condição de Produção, desvelamos uma rede imaginária que compõe a historicidade do sujeito escritor, rede que nos mostra em muitos dos seus versos a pátria que o relegou à diáspora, que o fez sentir que "a pátria somos nós" e "pátria é só a língua em que me digo", que não pode ser relegada às paredes silenciantes da memória oficial do estado colonial.

\section{Referências}

BACHELARD, G. A poética do espaço. São Paulo: Martins Fontes, 1998.

CHAVES, R. Angola e Moçambique: experiência colonial e territórios literários. Cotia: Ateliê Editorial, 2005.

COURTINE, J.-J. Análise do discurso político: discurso comunista endereçado aos cristãos. São Carlos: EDUFSCAR, 2009.

KNOPFLI, R. Obra Poética. Lisboa: Editorial da INCM, 2003.

LARANJEIRA, P. Ensaios Afro-literários. Coimbra: Novo Imbondeiro, 2001.

LOPES, O.; SARAIVA, A. J. História da Literatura Portuguesa. Porto: Porto Editora, 2012.

MONTEIRO, F. O país dos outros: a poesia de Rui Knopfli. Lisboa: Editorial da INCM, 2003.

ORLANDI, E. P. A Análise de Discurso: princípios e procedimentos. Campinas: Pontes, 1999.

. As Formas do Silêncio: No movimento dos sentidos. Campinas: Editora da UNICAMP, 1997.

PAZ, O. El Arco y la Lira. México: Fondo de Cultura Económica, 1993.

. Signos em Rotação. São Paulo: Editora Perspectiva, 2009.

Recebido em: 12/05/2018 Aceito em: 16/05/2018 